\title{
Highly reactive molecules: Examples for the interplay between theory and experiment
}

\author{
Günther Maier, Hans Peter Reisenauer, Thomas Preiss, Harald Pacl, Dorothée \\ Jürgen, Ralf Tross, and Stefan Senger \\ Institute of Organic Chemistry, Justus Liebig University, D-35392 Giessen, Germany
}

\begin{abstract}
Matrix isolation in combination with quantum chemical calculations is the method of choice for the study of highly reactive molecules. Different methods (A F) can be applied for the generation of the target molecules. Irradiation in a halogendoped xenon matrix may be a fundamentally new method which can be important in those cases in which previous methods cannot be applied.
\end{abstract}

Cyclobutadiene 1, cyclopropenylidene 2 and trimethylenemethane 3 are the parent molecules of three completely different families of conjugated hydrocarbons. Cyclobutadiene 1 is the first member of the series of cyclic conjugated hydrocarbons (Kekulé compounds); cyclopropenylidene 2, of cyclic conjugated carbenes; trimethylenemethane 3 , of the non- Kekulé hydrocarbons.

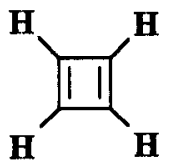

1

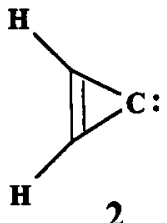

2<smiles>C=C(C)C</smiles>

3

During our studies of cyclobutadiene 1 some years ago (1), we wondered whether matrix-isolation IR spectroscopy might be also a good tool for the study of cyclopropenylidene 2 and trimethylenemethane 3 . This is indeed the case, as shown in this paper. Our efforts to isolate and identify 2 and 3 resulted in the development of new techniques to generate the target molecules. At the same time this report demonstrates the importance of the interplay between theory and experiment in elucidating the structure and specific properties of the matrix-isolated species.

\section{Cyclopropenylidenes}

We were able to prepare cyclopropenylidene for the first time by high-vacuum flash pyrolysis (method A) of the polycyclic precursor 4 and to isolate it in an argon matrix (2). The identification was based on the excellent agreement of the experimental and calculated (3) IR frequencies. A better candidate for the preparation of 2 is perester 5 (4). The best route is the thermal $\mathrm{HCl}$ elimination from 3-chlorocyclopropene $6(5,6)$

Cyclopropenylidene 2,S, which has a singlet ground state, can be photoisomerized in the matrix (method B) into triplet propargylene 7,T (4) which on further irradiation yields singlet vinylidenecarbene 8,S.

Originally propargylene 7,T was identified by its electron spin resonance (ESR) spectrum by Skell (7). Surprisingly the experimental IR spectrum of $7, T$ (8) did not show the expected triple bond stretching 
vibration around $2000 \mathrm{~cm}^{-1}$. Instead an absorbtion at $1620 \mathrm{~cm}^{-1}$ could be detected. This pointed out that triplet propargylene is a $\mathrm{C}_{3} \mathrm{H}_{2}$ isomer with unusual bonding (8). It was anticipated that 7 eventually has to be treated as a quasilinear molecule (8). Newer calculations (9) indicate that a $\mathrm{C}_{2}$ structure (as shown in formula $7, \mathbf{T}$ ) with two identical $\mathrm{CC}$ bonds is an energy minimum and gives an acceptable agreement between the calculated and experimental spectrum.

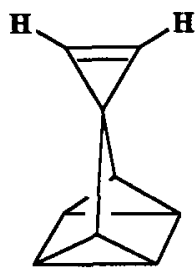

4

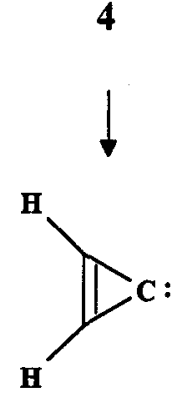

2,S<smiles>CC(C)COC(=O)C1(C(=O)OOC(C)C)C=C1</smiles>

5

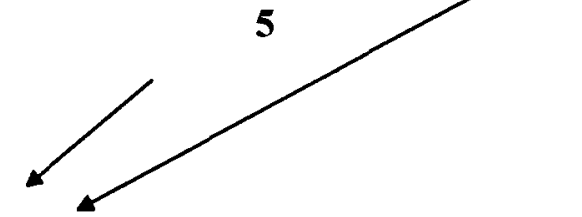<smiles>ClC1C=C1</smiles>

6<smiles>C=C=CC</smiles><smiles>C=C=C</smiles>

$8, S$

It is known that a halogen atom at the carbenic center stabilizes the singlet state by $\pi$-electron donation. So it might be expected that halogen-substituted propargylenes could have a singlet rather than a triplet ground state and they should show "normal" (acetylene-type) IR spectra.

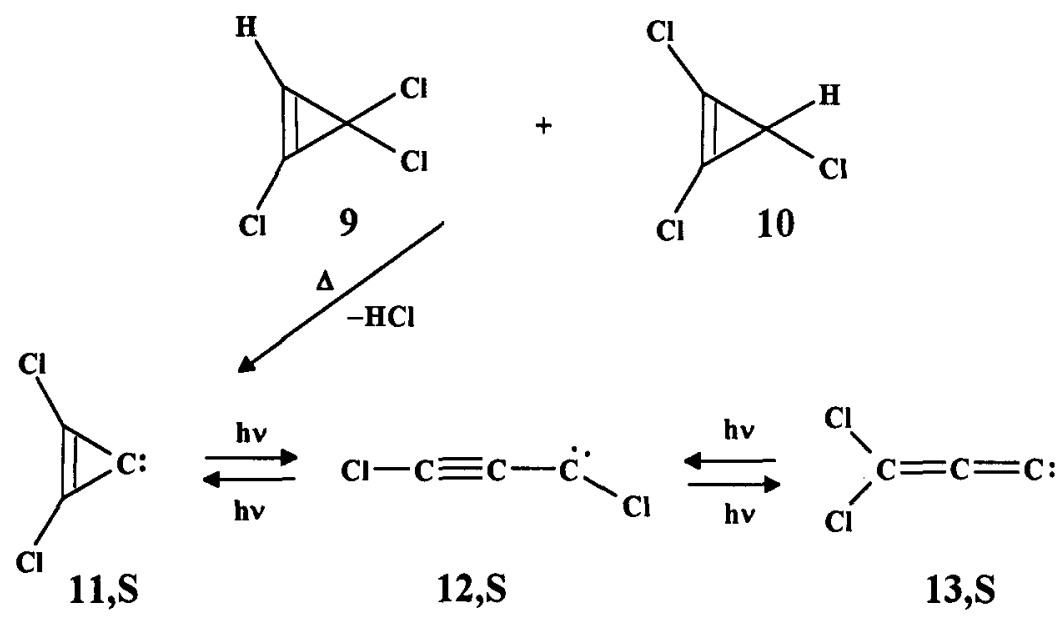

To test this prediction, matrix-isolated mono- and dichlorocyclopropenylidene were generated by highvacuum flash pyrolysis of the corresponding bi- and trichlorocyclopropenes. By subsequent photolysis they have been isomerized to the corresponding vinylidenecarbenes and propargylenes (5). All these carbenes, for example 11, 12 and 13, (found by pyrolysis of $9 / 10$ ) have singlet electronic ground states. 
In contrast to the unsubstituted triplet propargylene, the experimental IR spectrum of dichloro derivative $12, \mathrm{~S}$ has a structure with a "fixed" CC triple and CC single bond, again in accordance with the calculated spectrum.

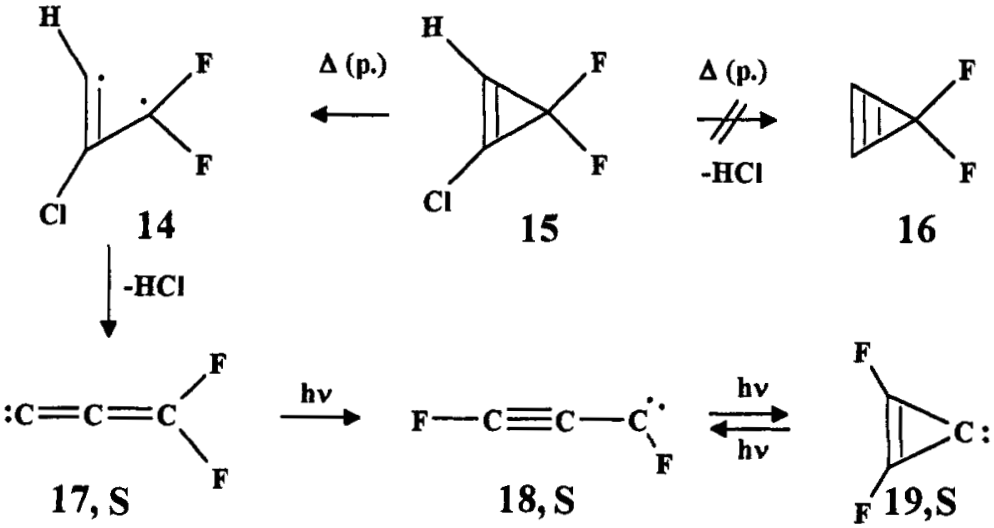

The difluoro derivatives 17,18 and 19 have also been calculated (10) to have singlet ground states. Cyclopropene 15 is not the ideal candidate for a $\mathrm{HCl}$ elimination, since this reaction should lead to the highly strained cyclopropyne 16. Therefore it is no surprise that the "classical" pyrolysis (method A) of 15 gives only traces of vinylidenecarbene 17 (probably via diradical 14). A reasonable amount of 17 could only be generated by pulsed flash pyrolysis (method C) of 15 (11). On photolysis 17 is isomerized to propargylene 18 and finally to difluorocyclopropenylidene 19 . The identification of 17,18 and 19 could easily be achieved by comparison of the calculated (10) with the experimental (11) IR spectra.

\section{Silacyclopropenylidene, Silacyclopropyne}

Pulsed flash pyrolysis in combination with matrix isolation (method C) can also be used for the isolation of the sila analogues of 2,7 and 8 . According to calculations (12) 1-silacyclopropenylidene 24 is expected to be the most stable $\mathrm{C}_{2} \mathrm{H}_{2} \mathrm{Si}$ isomer (13). Indeed, when gaseous mixtures of disilane 21 and argon were subjected to pulsed flash pyrolysis and the products condensed onto the matrix window at $10 \mathrm{~K}$, apart from the bands for trimethylsilane 23 those of another compound could be detected (14). This substance has been identified as 24 , even though the structure of reactant 21 suggests formation of ethynylsilylene 25. This isomer 25 is formed upon irradiation $(313 \mathrm{~nm})$ of matrix-isolated 24 . The broad UV/Vis absorption of 25 also allows the photoisomerisation of 25 into 26 (14).

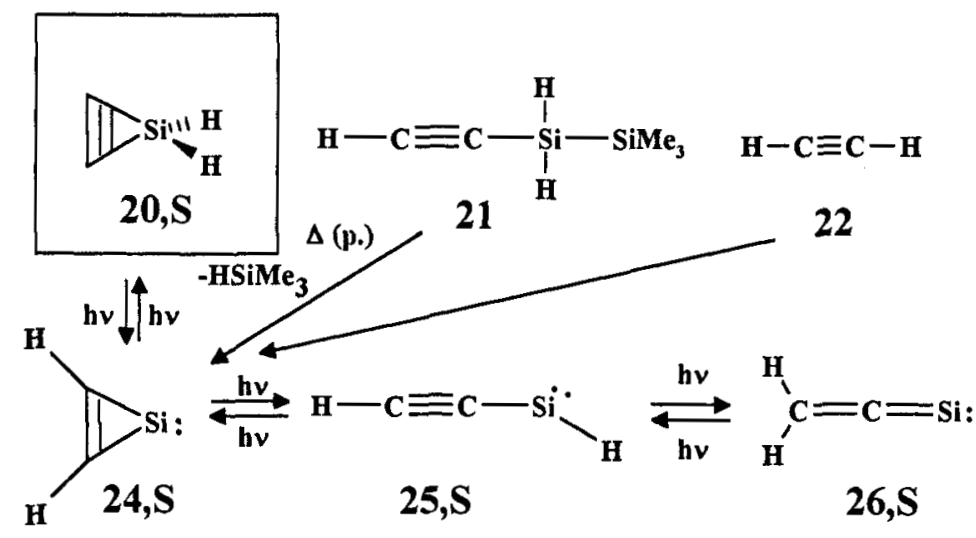


If 24 is irradiated with light of wavelength $\lambda=254 \mathrm{~nm}$ besides 25 another $\mathrm{C}_{2} \mathrm{H}_{2} \mathrm{Si}$ isomer is formed (14). Most surprisingly this new compound turned out to be 1 -silacyclopropyne $20(14,15)$. Because of some inconsistencies in the comparison between the calculated and experimental IR spectrum the final proof for the structure of 20 was only possible by the study of the ${ }^{13} \mathrm{C}$ isotopomer of 20 (15).

Whereas 1-silacyclopropenylidene 24 - the same is true for cyclopropenylidene 2,5 - can be described by a Lewis structure with a delocalized three-center $\pi$-bond orbital, 1 -silacyclopropyne $\mathbf{2 0}$ is characterized by a localized $\pi$-bond orbital and an almost non-bonding CC- $\sigma$ orbital (15). The formal triple bond drawn in formula 20 in reality does not exist. Silacyclopropyne is probably the most strained ring compound ever prepared (the calculated ring strain energy is roughly $100 \mathrm{kcal} / \mathrm{mol}$, i. e. $33 \mathrm{kcal} / \mathrm{mol}$ per ring bond).

In conclusion of this chapter it should be mentioned, that 1-silacyclopropenylidene 24 is also formed when atomic silicon - generated by thermal evaporation - is treated with acetylene in an argon matrix (method D) (16). On the other hand 1-silacyclopropene, also a long sought-after compound, can be synthesized by pyrolysis of 1,1,1-trimethyl-2-vinyldisilane (triple bond in 21 replaced by a vinylgroup) (17).

\section{Trimethylenemethane}

Compound 3 was first prepared by Dowd (18) upon photolysis of 4-methylenedihydropyrazole 27 and later of 3-methylencyclobutanone $\mathbf{2 8}$ in an organic matrix at liquid nitrogen temperature. Its existence was proved by ESR spectroscopy (18). Our previous attempts (19) to isolate 3 in an argon matrix gave the following results: Irradiation of 27 in argon at $10 \mathrm{~K}$ gave a well resolved ESR spectrum of 3, but in the IR spectrum only the bands of methylenecyclopropane were recognizable.

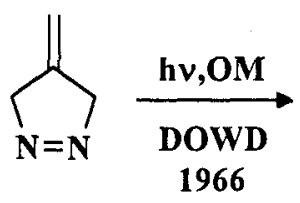

27

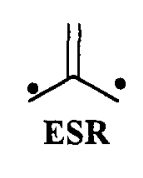

3

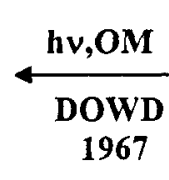

1967

28

Despite these diappointing results we recently reopened our investigations, and our efforts have been rewarded (20). To make a long story short: We found that methylenecyclopropane 29 opens to trimethylenemethane 3 upon irradiation in a halogen-doped xenon matrix at $10 \mathrm{~K}$ (method $\mathrm{E}$ ), but not in an argon matrix $(20,21)$. The identification of trimethylenemethane 3 formed is based primarily on the comparison of the measured with the calculated (20-22) IR spectrum.

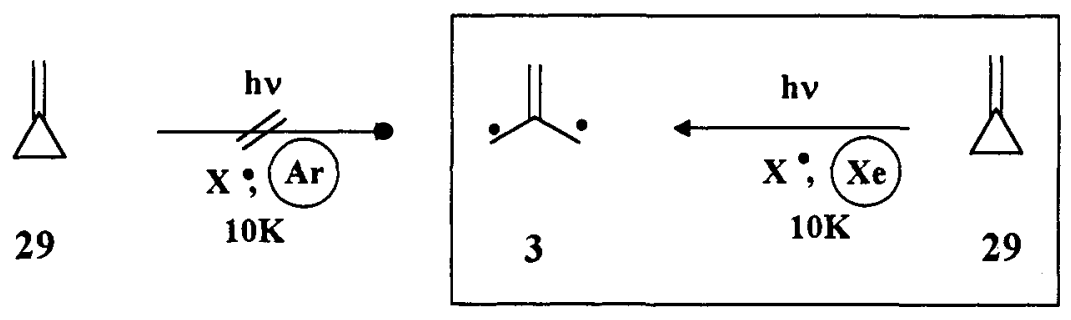

How does one explain the photoexcitation of 29, a compound that does not absorb in the UV range? We assume that the halogen atoms $\left(\mathrm{I}^{*}, \mathrm{Br}^{*}\right.$ or $\left.\mathrm{Cl}^{\circ}\right)$ form exciplexes 30 with xenon when irradiated. These exciplexes represent a delocalized hole in the xenon valence band (23). They can either relax to the more 
stable exciplexes 31 (23) or can be trapped to the localized charge-transfer complexes 32 . The energy stored in the charge separation of the cation radical and halogen anion is released instantaniously on neutralization and is sufficient for the bond cleavage in the substrate molecule. For neutral $\mathbf{2 9}$ the barrier to overcome is $47 \mathrm{kcal} / \mathrm{mol}$ (24), for the radical cation of 29 the calculated barrier is $15.7 \mathrm{kcal} / \mathrm{mol}(25)$.

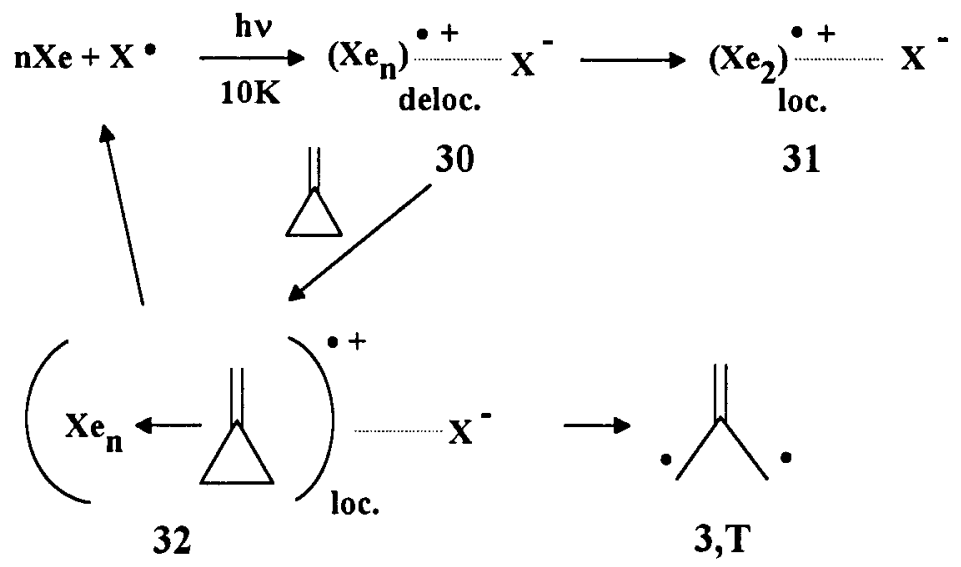

The same procedure (method E) also works in the case of cyclopropane (26) and cyclobutane (27). Again ring opening (33 $\rightarrow \mathbf{3 4} \rightarrow \mathbf{3 5}$ or $\mathbf{3 6} \rightarrow \mathbf{3 7} \rightarrow \mathbf{3 8}+39$ ) is observed upon irradiation in a halogen-doped xenon matrix.
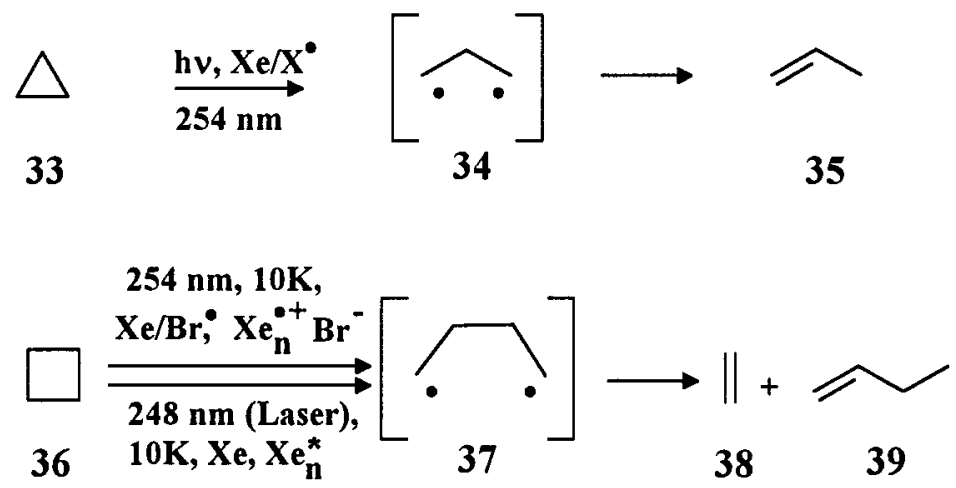

Cyclobutane can not only be cleaved (mainly into ethene 38 and 1-butene 39) in the presence of a bromine atom via an exciplex of type 32, but also upon irradiation with a KrF-laser $(\lambda=248 \mathrm{~nm})$ at $10 \mathrm{~K}$ in absence of the halogen (method F). The excitation of the non-doped xenon matrix with $248 \mathrm{~nm}$-light demands a two photon process in order to form the "free" exciton $\mathrm{Xe}_{\mathrm{n}}{ }^{*}$, which now functions as the energy carrier. 


\section{References}

1. Review: G. Maier, Angew. Chem. 100, 317-341 (1988); Angew. Chem. Int. Ed. Engl. 27, 309332 (1988), and references therein.

2. H. P. Reisenauer, G. Maier, A. Riemann, R. W. Hoffmann, Angew. Chem. 96 , 596 (1984); Angew. Chem. Int. Ed. Engl. 23, 641 (1984).

3. T. J. Lee, A. Bunge, H. F. Schaefer III, J. Am. Chem. Soc. 107, 137 (1985).

4. G. Maier, H. P. Reisenauer, W. Schwab, P. Cársky, B. A. Hess, Jr., L. J. Schaad, J. Am. Chem. Soc. $109,5183-5188$ (1987).

5. G. Maier, Th. Preiss, H. P. Reisenauer, B. A. Hess, Jr., L. J. Schaad, J. Am. Chem. Soc. 116, 2014-2018 (1994).

6. H. Clauberg, P. Chen, J. Am. Chem. Soc. 113, 1445 (1991).

7. R. A. Bernheim, R. J. Kempf, J. V. Gramas, P. S. Skell, J. Chem. Phys. 43, 196 (1965).

8. G. Maier, H. P. Reisenauer, W. Schwab, P. Cársky, V. Spirko, B. A. Hess, Jr., L. J. Schaad, J. Chem. Phys. 91, 4763-4773 (1989).

9. R. Herges, A. Mebel, J. Am. Chem. Soc. 116, 8229-8237 (1994).

10. V. Jonas, M. Böhme, G. Frenking, J. Phys. Chem. 96, 1640-1648 (1992).

11. G. Maier, Th. Preiss, H. P. Reisenauer, Chem. Ber. 127, 779-782 (1994).

12. G. Frenking, R. B. Remington, H. F. Schaefer III, J. Am. Chem. Soc. 108, 2169-2173 (1986). -

G. Vacek, B. T. Colgrove, H. F. Schaefer III, ibid. 113, 3192-3193 (1991)

13. Mass spectrometric detection: R. Srinivas, D. Sülzle, T. Weiske, H. Schwarz, Int. J. Mass Spectrom. Ion Processes 107, 369-376 (1991).

14. G. Maier, H. P. Reisenauer, H. Pacl, Angew. Chem. 106, 1347-1349 (1994); Angew. Chem. Int. Ed. Engl. 33, 1248-1250 (1994).

15. G. Maier, H. Pacl, H. P. Reisenauer, A. Meudt, R. Janoschek, J. Am. Chem. Soc., in print.

16. H. P. Reisenauer, unpublished.

17. G. Maier, H. Pacl, H. P. Reisenauer, Angew. Chem. 107, 1627-1629 (1995); Angew. Chem. Int. Ed. Engl. 34, 1439-1441 (1995).

18. P. Dowd, J. Am. Chem. Soc. 88, 2587 (1966). - P. Dowd, K. Sachdev, J. Am. Chem. Soc. $\underline{89}$, 715 (1967).

19. K. Lanz, diploma work, Justus Liebig University Giessen, (1988).

20. G. Maier, H. P. Reisenauer, K. Lanz, R. Tross, D. Jürgen, B. A. Hess, Jr., L. J. Schaad, Angew. Chem. 105, 119-120 (1993); Angew. Chem. Int. Ed. Engl. 32, 74-76 (1993).

21. G. Maier, D. Jürgen, R. Tross, H. P. Reisenauer, B. A. Hess, Jr., L. J. Schaad, Chem. Phys. $\underline{189}$, 383-399 (1994).

22. C. P. Blahous III, Y. Xie, H. F. Schaefer III, J. Chem. Phys. 92, 1174 (1990).

23. I. Last, T. F. George, M. E. Fajardo, V. A. Apkarian, J. Chem. Phys. 87, 5917 (1987), - M. E. Fajardo, V. A. Apkarian, J. Chem. Phys. 85, 5660 (1986). - V. A. Apkarian, M. E. Fajardo, J. Chem. Phys. 89, 4102 (1988). - M. E. Fajardo, V. A. Apkarian, J. Chem. Phys. 89 , 4124 (1988).

24. J. P. Chesick, J. Am. Chem. Soc. 85, 2720 (1963).

25. R. Janoschek, private communication.

26. G. Maier, S. Senger, Angew. Chem. 106, 605-606 (1994); Angew. Chem. Int. Ed. Engl. 33, 558559 (1994).

27. G. Maier, S. Senger, Liebigs Ann., in print. 